\title{
Low and moderate-fat plant sterol fortified soymilk in modulation of plasma lipids and cholesterol kinetics in subjects with normal to high cholesterol concentrations: report on two randomized
} crossover studies

\author{
Todd C Rideout*†, Yen-Ming Chan ${ }^{\dagger}$, Scott V Harding and Peter JH Jones
}

Address: Richardson Centre for Functional Foods and Nutraceuticals, University of Manitoba, Winnipeg, Manitoba R3T 6C5, Canada

Email: Todd C Rideout* - t_rideout@umanitoba.ca; Yen-Ming Chan - chany@cc.umanitoba.ca; Scott V Harding - scott_harding@umanitoba.ca; Peter JH Jones - peter_Jones@umanitoba.ca

* Corresponding author †Equal contributors

Published: 20 October 2009

Lipids in Health and Disease 2009, 8:45 doi:I0.1 I86/1476-5IIX-8-45

This article is available from: http://www.lipidworld.com/content/8/1/45

(c) 2009 Rideout et al; licensee BioMed Central Ltd.

This is an Open Access article distributed under the terms of the Creative Commons Attribution License (http://creativecommons.org/licenses/by/2.0), which permits unrestricted use, distribution, and reproduction in any medium, provided the original work is properly cited.
Received: 3 September 2009

Accepted: 20 October 2009

\begin{abstract}
Background: Although consumption of various plant sterol (PS)-enriched beverages is effective in lowering plasma cholesterol, the lipid-lowering potential of PS in a soymilk format has not been investigated thoroughly. Therefore, to evaluate the efficacy of PS-enriched soy beverages on plasma lipids and cholesterol kinetics, we conducted two separate $28 \mathrm{~d}$ dietary controlled cross-over studies. In study I, the cholesterol-lowering efficacy of a low-fat (2 g/serving) PS enriched soy beverage was examined in 33 normal cholesterolemic subjects in comparison with $1 \%$ dairy milk. In study 2, we investigated the efficacy of a moderate-fat ( $3.5 \mathrm{~g} / \mathrm{serving})$ PS-enriched soy beverage on plasma cholesterol concentrations and cholesterol kinetic responses in 23 hypercholesterolemic subjects compared with $1 \%$ dairy milk. Both the low and moderate-fat PSenriched soymilk varieties provided $1.95 \mathrm{~g}$ PS/d. Endpoint plasma variables were analyzed by repeated-measures ANOVA using baseline values as covariates for plasma lipid measurements.
\end{abstract}

Results: In comparison with the I\% dairy milk control, the low-fat soy beverage reduced $(P<0.05)$ total and LDL-cholesterol by 10 and $13 \%$, respectively. Consumption of the moderate-fat PSenriched soy beverage reduced $(P<0.05)$ plasma total and LDL-cholesterol by 12 and $15 \%$ respectively. Fasting triglycerides were reduced by $9.4 \%$ following consumption of the moderatefat soy beverage in comparison with the $1 \%$ dairy milk. Both low and moderate-fat PS-enriched soy varieties reduced $(P<0.05)$ LDL:HDL and TC:HDL ratios compared with the $1 \%$ dairy milk control. Consumption of the moderate-fat PS-enriched soymilk reduced $(P<0.05)$ cholesterol absorption by $27 \%$, but did not alter cholesterol synthesis in comparison with $1 \%$ dairy milk.

Conclusion: We conclude that, compared to $1 \%$ dairy milk, consumption of low and moderatefat PS-enriched soy beverages represents an effective dietary strategy to reduce circulating lipid concentrations in normal to hypercholesterolemic individuals by reducing intestinal cholesterol absorption.

Trial registration (clinicaltrials.gov): NCT00923403 (Study I), NCT0092439I (Study 2). 


\section{Background}

Although drug treatment is effective in the management of dyslipidemia, diet-based monotherapies or combination dietary approaches that reduce the incidence of arterial vascular diseases will be integral to sustainable health care systems of the future [1]. Consumption of plant sterols (PS), constituents found in plants that chemically resemble cholesterol, is a well-defined dietary lipid-lowering strategy with repeated demonstrations of cholesterol reductions in human clinical investigations in the range of $8-15 \%$ [2-4]. However, it is increasingly clear that the food/beverage format used as the PS delivery vehicle may impact PS solubility and hence modulate intestinal cholesterol absorption and the magnitude of cholesterol-lowering $[5,6]$. For instance, although cholesterol reductions are observed following consumption of PS-fortified products including juice [7], margarine [8], and dressings [9], debate continues surrounding the lipid-lowering efficacy of low-fat vs moderate and high-fat PS-fortified products $[10,11]$.

Considering the substantial increase in soymilk consumption in North America as an alternative to dairy milk, several studies have compared lipid-lowering responses of soymilk versus dairy milk [12-14]. While previous animal model investigations suggest that combination therapy of PS and soy protein reduces circulating cholesterol concentrations beyond that observed with either therapy alone [15], only one published report has investigated soymilk as a potential PS delivery beverage in human subjects; and this study was conducted without the advantage of a precisely controlled feeding design [16]. Furthermore, no information is available concerning the modulation of intestinal cholesterol absorption and synthesis in response to PS fortified soymilk. Given the reputed health benefits associated with the protein, isoflavone, saponin, and fiber components of soy [17], a unique opportunity exists to expand on these benefits through use of a PS fortified soy beverage. Here, we report on two separate controlled clinical feeding studies evaluating the efficacy of PS-enriched soy beverages differing in fat content on plasma lipids in comparison to a $1 \%$ dairy milk control. In study 1 , our objective was to examine plasma lipids in response to the consumption of a low-fat ( $2 \mathrm{~g} /$ serving) PSenriched soy beverage. In study 2 , our objectives were to investigate plasma lipid and cholesterol kinetic responses following consumption of a moderate-fat ( $3.5 \mathrm{~g} /$ serving) PS enriched soy beverage.

\section{Results \\ Study I - Low-Fat PS-Enriched Soy Beverage}

Of the forty-two subjects initially recruited for study, 33 subjects ( 15 males and 18 females) completed both experimental phases. Nine subjects dropped out during the first phase due to difficulties with consuming study diets ( $\mathrm{n}=$ $2)$, relocation to another city $(\mathrm{n}=1)$, problems with daily centre visiting $(\mathrm{n}=4)$, and personal reasons $(\mathrm{n}=2)$. Palatability and texture of the PS-enriched soymilk beverage were assessed as highly acceptable. No side effects associated with soymilk or control milk consumption were reported.

Fasting endpoint lipid concentrations in response to lowfat PS-enriched soymilk consumption are presented in Table 1 . TC concentrations were reduced $(P<0.0001)$ by $10 \%$ following consumption of the low-fat PS enriched soy beverage $(203.40 \pm 6.17 \mathrm{mg} / \mathrm{dl} ; 5.26 \pm 0.16 \mathrm{mmol} / \mathrm{L})$ in comparison with the $1 \%$ dairy milk control (224.28 \pm $6.57 \mathrm{mg} / \mathrm{dl} ; 5.80 \pm 0.17 \mathrm{mmol} / \mathrm{L})$. Plasma LDL-C concentrations were reduced $(P<0.0001)$ by $13 \%$ following lowfat PS-enriched soymilk consumption $(123.74 \pm 5.80 \mathrm{mg} /$ $\mathrm{dl} ; 3.20 \pm 0.15 \mathrm{mmol} / \mathrm{L}$ ) in comparison with the $1 \%$ dairy milk $(141.53 \pm 5.80 \mathrm{mg} / \mathrm{dl} ; 3.66 \pm 0.15 \mathrm{mmol} / \mathrm{L})$. Low-fat PS-enriched soymilk consumption decreased $(P<0.05)$ the LDL:HDL (2.74 vs 3.21) and TC:HDL (4.71 vs 5.05 ) ratios relative to $1 \%$ dairy milk. No treatment effects were observed in HDL-C and TG concentrations between the two groups.

Further analyses of TC and LDL-C were conducted in a subgroup $(n=14)$ of subjects with initial LDL-C concentrations above $3.4 \mathrm{mmol} / \mathrm{L}$. Plasma TC concentrations

Table I: Fasting plasma cholesterol concentrations in hypercholesterolemic individuals in response to the consumption of a low-fat and moderate-fat plant sterol-enriched soymilk and I\% dairy milk for 29 days ${ }^{a}$

\begin{tabular}{lcccc}
\hline Plasma lipids (mg/d) & I\% Dairy Milk & $\begin{array}{c}\text { Study I } \\
\text { Low-fat Soymilk }\end{array}$ & I\% Dairy Milk & $\begin{array}{c}\text { Study } 2 \\
\text { Moderate-fat Soymilk }\end{array}$ \\
\hline Total cholesterol & $224.28 \pm 6.57$ & $203.40 \pm 6.19^{*}$ & $242.85 \pm 10.44$ & $216.16 \pm 10.44 \dagger$ \\
LDL cholesterol & $141.53 \pm 5.80$ & $123.74 \pm 5.80^{*}$ & $162.41 \pm 8.50$ & $139.21 \pm 7.73 \dagger$ \\
HDL cholesterol & $47.17 \pm 2.32$ & $46.40 \pm 2.32$ & $47.56 \pm 2.33$ & $44.47 \pm 2.71$ \\
LDL:HDL & $3.21 \pm 0.20$ & $2.83 \pm 0.18^{*}$ & $3.52 \pm 0.25$ & $3.18 \pm 0.23 \dagger$ \\
Total:HDL & $5.05 \pm 0.26$ & $4.71 \pm 0.27^{*}$ & $5.38 \pm 0.35$ & $4.75 \pm 0.33^{\dagger}$ \\
Triglycerides & $178.03 \pm 15.06$ & $172.72 \pm 16.83$ & $185.12 \pm 27.46$ & $169.18 \pm 25.69 \dagger$ \\
\hline
\end{tabular}

aData presented as mean \pm SEM, $n=33$ for study $I ; n=23$ for study 2 .

*, significantly different from $1 \%$ dairy milk in study $\mathrm{I} ; \dagger$, significantly different from $1 \%$ dairy milk in study 2 . 
decreased $(P<0.0001)$ by $9.5 \%$ following consumption of the low-fat PS-enriched soymilk, as compared to controls. Subjects consuming the low-fat PS-enriched soymilk had a $12 \%$ reduction in LDL-C concentrations $(P=$ $0.0002)$, relative to the $1 \%$ dairy milk.

\section{Study 2 - Moderate-Fat PS Enriched Soy Beverage}

Of the 32 subjects initially recruited for study, 23 completed (10 males and 13 females) both experimental phases. Of the 9 subjects who did not complete the trial, 3 dropped out during the initial days of the study citing an inability to comply with dietary restrictions. The 6 remaining dropouts left the study following completion of the first phase due to family $(n=2)$, health $(n=1)$, and work-related issues $(n=3)$. Palatability and texture of the PS-enriched soymilk beverage were assessed as highly acceptable. No side effects associated with soymilk or control milk consumption were reported.

Fasting endpoint lipid concentrations in response to PSenriched moderate-fat soymilk consumption are presented in Table 1 . TC was reduced by $12 \%(P<0.0001)$ in the PS-enriched soymilk group $(216.16 \pm 10.44 \mathrm{mg} / \mathrm{dl}$; $5.59 \pm 0.27 \mathrm{mmol} / \mathrm{L})$ in comparison with the $1 \% \mathrm{milk}$ control $(242.84 \pm 10.44 \mathrm{mg} / \mathrm{dl} ; 6.28 \pm 0.27 \mathrm{mmol} / \mathrm{L})$. Subjects receiving the PS-enriched soymilk displayed a $15 \%$ reduction $(P<0.0001)$ in LDL-C $(139.21 \pm 7.73 \mathrm{mg} /$ $\mathrm{dl} ; 3.60 \pm 0.20 \mathrm{mmol} / \mathrm{L})$ in comparison to $1 \%$ dairy milk $(162.41 \pm 8.50 \mathrm{mg} / \mathrm{dl} ; 4.20 \pm 0.22 \mathrm{mmol} / \mathrm{L})$. PS-enriched soymilk consumption did not alter $(P>0.05)$ HDL-C concentrations. However, PS enriched soymilk consumption decreased $(P<0.05)$ endpoint LDL:HDL $(3.18$ vs. 3.52) and TC:HDL ratios ( 4.75 vs. 5.38 ) in comparison to the $1 \%$ dairy milk control. Subjects consuming the PSenriched soymilk displayed a $9 \%$ reduction $(P=0.02)$ in plasma TG in comparison to those receiving the $1 \%$ dairy milk control.

Cholesterol absorption, as measured by the area under the $[3,4]-{ }^{13} \mathrm{C}$ cholesterol RBC enrichment curve, was reduced $(P=0.02)$ by $27 \%$ in response to the consumption of PSenriched soymilk in comparison to the $1 \%$ dairy milk control (Figure 1). In contrast, cholesterol synthesis, as measured by deuterium incorporation, did not differ $(P=$ 0.45 ) between the PS-enhanced soymilk and 1\% dairy milk groups $(5.69 \pm 0.63$ vs $5.08 \pm 0.79 \% /$ day $)$.

\section{Discussion}

Consumption of both low and moderate-fat PS enriched soy beverages reduced fasting total and LDL-C in comparison with $1 \%$ dairy milk. Although direct statistical comparison between the two clinical studies is not possible, the numerical plasma cholesterol responses between the two studies suggest that the fat content of the soymilk had little impact on vehicle performance as LDL-C reductions

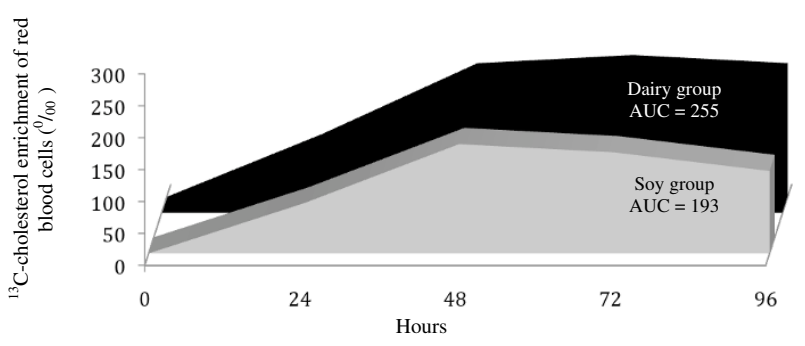

\section{Figure I}

${ }^{13} \mathrm{C}$-cholesterol enrichment of red blood cells at 24, 48,72 , and $96 \mathrm{~h}$ following ingestion of $75 \mathrm{mg}$ of $[3,4]$ ${ }_{13} \mathrm{C}$-cholesterol in response to consumption of moderate-fat plant sterol enriched soymilk. Values are mean $\pm \operatorname{SEM}$ ( $n=17$ for soy group, 18 for dairy group).

following consumption of the low and moderate-fat soymilk beverages were similar (13 and 15\%, respectively). Direct comparisons of the clinical effectiveness of PS products between studies are often limited by differences in study design, as cholesterol reductions in response to PS consumption are modulated by multiple factors including background diet [18], PS dose [19] and form [20], frequency of PS consumption [21], level and type of fat in food vehicle [6], and baseline LDL-C concentration of study subjects [18]. As the background diet and factors pertaining to the dose, form and frequency of PS consumption were identical between our two studies, the comparable cholesterol-lowering response between the soymilk beverages may help clarify confusion that exists surrounding the effectiveness of PS enriched beverages with differing fat content. The only minor difference between our study protocols was the lower LDL-C baseline concentrations of the low-fat soy beverage group compared with the moderate-fat soymilk study subjects. It has been suggested that subjects with higher LDL-C may respond more favourably, and with further cholesterol reductions, than individuals with lower LDL-C concentrations [19]. However, when the analysis was conducted in hypercholesterolemic subjects with entry LDL-C concentrations above $3.4 \mathrm{mmol} / \mathrm{L}$, TC and LDL-C reductions following PS-enriched low-fat soymilk consumption were similar to those reported for the entire study population. Therefore, our results suggest that patients with lower LDL-C concentrations may also benefit from the consumption of PS enriched soymilk.

Consumption of the moderate-fat PS enriched soymilk was associated with a $9 \%$ reduction in circulating triglycerides. Although PS consumption is not traditionally associated with modulation of triglyceride metabolism, Plat et al. recently observed a reduction in circulating TAG by $27.5 \%$ in metabolic syndrome patients with hypertriglyceridemia following the consumption of a PS yogurt drink 
[22]. Furthermore, this report follows a recent meta-analysis suggesting a PS-induced modulation of plasma triglycerides [23], although previous meta-analyses have failed to establish this relationship $[6,19]$. This PSinduced reduction in plasma triglycerides was only observed in subjects from study 2 who had elevated triglyceride concentrations compared to study 1 subjects, giving merit to Plat's speculation that modulation of triglycerides in response to PS consumption may be more readily detected in study populations with high baseline triglycerides.

It is increasingly clear that some individuals respond with major shifts in lipid profiles to PS consumption whereas others are much less sensitive to PS challenges. This variability of responsiveness is likely associated with single nuclear polymorphisms (SNPs) in Niemann-Pick C1-like 1 (NPC1L1) and ATP binding cassette proteins G5 (ABCG5) and G8 (ABCG8), genes that regulate intestinal sterol absorption and efflux [24,25]. Although the two soymilk beverages were associated with similar LDL-C reductions, it is clear that the low-fat soymilk study population included more non-responders that subjects in the moderate-fat soymilk study (Figure 2). While consumption of the moderate-fat soy beverage was associated with an LDL-C lowering ranging from from 2 to 38\%, LDL-C reductions following the low-fat soy beverage ranged from -33 to $+37 \%$, with 9 subjects displaying increased LDL-C following the low-fat soy treatment.

Cholesterol absorption was reduced by $27 \%$ following consumption of the moderate-fat PS fortified soy beverage. The cholesterol-lowering effects of PS are related to modulation of intestinal cholesterol absorption through several distinct mechanisms including interference with

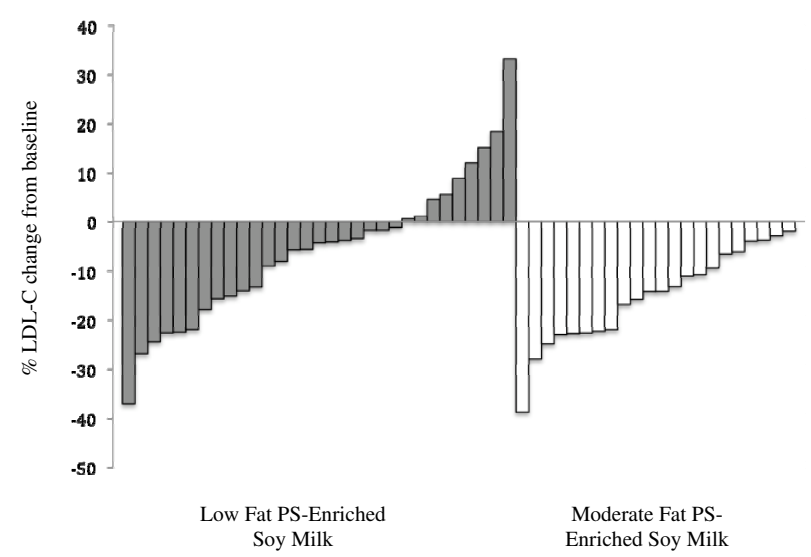

Figure 2

Individual \% changes in LDL-C from baseline in response to the consumption of a low and moderatefat PS-enriched soy beverage. the micellular cholesterol incorporation [26], competition with dietary and biliary cholesterol for uptake through the brush border NPC1L1 [27], and reduction in cholesterol esterification and chylomicron assembly within the intestinal enterocyte [28]. Surprisingly, although previous investigations typically report compensatory increases in cholesterol synthesis in response to PS consumption $[29,30]$, no difference was observed in cholesterol synthesis between the moderate-fat PS fortified soy beverage and control group in the current study. The hepatic expression of genes that regulate cholesterol synthesis and plasma LDL-C trafficking, including 3-hydroxy3-methyl-glutaryl-CoA reductase, sterol-regulatory element binding protein 2, and LDL-receptor, have been shown to be transcriptionally regulated by individual protein and/or isoflavone components of soy [31,32]. Therefore, it can be speculated that specific bioactive components inherent in the soy beverage may have suppressed the increase in cholesterol synthesis typically observed following PS consumption. Alternatively, consumption of isolated soy protein has been reported to increase cholesterol FSR by $7.6 \%$ in hypercholesterolemic human subjects compared with animal protein consumption [33]. However, the effects of whole soymilk consumption on cholesterol synthesis has not been previously investigated.

\section{Conclusion}

Dietary approaches effective in reducing LDL-C are critical to the development of sustainable health care systems. Incorporation of PS into a daily dietary regimen is an effective approach to improving dyslipidemia and potentially reducing the incidence of cardiovascular diseases. However, the food/beverage that is used to deliver an effective PS dose is an important factor affecting the cholesterol-lowering response. Results of this study suggest that, compared with $1 \%$ dairy milk, consumption of low and moderate-fat PS-enriched soymilk beverages are effective food based therapeutic strategies for cardiovascular disease management through reduction of plasma lipids and modulation of intestinal cholesterol absorption in normal to hypercholesterolemic subjects.

\section{Methods Subjects}

Studies were conducted at the Clinical Nutrition Research Unit at the Richardson Centre for Functional Foods and Nutraceuticals (RCFFN), University of Manitoba. Subjects were recruited from the Winnipeg area using newspaper and radio endorsements, poster advertisements, and flyer distributions. Potential subjects, deemed eligible following an initial phone screening, visited the RCFFN for plasma cholesterol screening. Healthy males and females between the ages of 19-60 y with a body mass index (BMI) between $20-34 \mathrm{~kg} / \mathrm{m}^{2}$ were recruited who were free of thy- 
roid disorders, kidney disease, diabetes mellitus, and heart disease, and were not currently taking lipid-lowering medications. Study 1 included normal to hypercholesterolemic subjects with a fasting plasma LDL-cholesterol (LDL-C) between 2.1-5.2 mmol/L and TG below 2.82 $\mathrm{mmol} / \mathrm{L}$. Study 2 included hypercholesterolemic subjects with a LDL-C greater than $3.4 \mathrm{mmol} / \mathrm{L}$ and TG below 2.82 $\mathrm{mmol} / \mathrm{L}$. Baseline characteristics of subjects who completed the study are presented in Table 2 . To confirm individual health status, all subjects underwent a complete physical examination conducted by the study physician. The study protocols were approved by the Bioethical Research Ethics Board (BREB) at the University of Manitoba. All subjects signed informed consent to participate in the study.

\section{Study design and protocol}

Studies were carried out as 28-d controlled feeding trials using precisely prepared diets in a randomized crossover, two period design. Experimental periods were separated by a 4 -wk washout period during which the subjects consumed his/her habitual diets. All meals were prepared at the Richardson Clinical Nutrition Research Unit as a 3day rotating menu to provide the subjects with a variety of food during their experimental phases. Using a nutrient composition database (Food Processor, ESHA Research, Salem, OR), the diets were designed to contain 35\% of energy as fat, $50 \%$ as carbohydrate and $15 \%$ as protein and meet the energy requirements of each subject using the Mifflin equation [34]. Subjects were randomly assigned to one of two experimental groups: the control group receiving $1 \%$ dairy milk or the treatment group receiving the fortified soy beverage providing $1.95 \mathrm{~g}$ PS/d (PS-enriched soymilks supplied by Whitewave Foods, Inc.) (Table 3). Enriched soy and $1 \%$ dairy milks were provided as $3(240 \mathrm{ml})$ tetra-paks per day, 1 consumed with each meal. To monitor compliance, subjects consumed

Table 2: Baseline characteristics of subjects who completed the studies $^{\mathbf{a}}$

\begin{tabular}{lcc}
\hline & Study Ib & Study 2c \\
\hline Characteristic & Mean \pm SE & Mean \pm SE \\
Anthropometric measurements & & \\
$\quad$ Age (years) & $43.00 \pm 2.37$ & $43.9 \pm 0.3$ \\
Height (m) & $1.68 \pm 1.83$ & $1.66 \pm 0.02$ \\
Initial body weight $(\mathrm{kg})$ & $83.21 \pm 3.37$ & $82.8 \pm 4.0$ \\
Initial BMl $\left(\mathrm{kg} / \mathrm{m}^{2}\right)$ & $29.08 \pm 0.97$ & $30.0 \pm 1.5$ \\
Plasma lipids $(\mathrm{mg} / \mathrm{dl})$ & & \\
$\quad$ Total cholesterol & $210.36 \pm 5.80$ & $249.80 \pm 11.60$ \\
LDL-cholesterol & $129.54 \pm 5.03$ & $163.57 \pm 8.12$ \\
HDL-cholesterol & $47.56 \pm 2.32$ & $49.11 \pm 2.70$ \\
Triglycerides & $165.63 \pm 15.05$ & $206.37 \pm 34.54$ \\
\hline
\end{tabular}

aData presented as mean \pm SEM; $n=33$ for study I; $n=23$ for study 2 bLow-fat plant sterol-enriched soymilk study

cModerate-fat plant sterol-enriched soymilk study their daily supper meal in conjunction with one treatment or control beverage under direct supervision. The remaining meals and treatments were packed for take-out. Subjects were instructed to shake the tetra paks prior to drinking, consume only foods and beverages provided by the clinical research team, and return the empty containers to ensure that the beverage was properly administered.

\section{Outcome measurements}

Twelve-hour fasting blood samples $(26 \mathrm{ml})$ were collected on days 1 and 2 (baseline) and 29 and 30 (endpoint) during each phase. On day 24 of each experimental phase of study 2 (moderate-fat soymilk study only), a fasting baseline blood sample $(0 \mathrm{~h})$ was taken prior to administration of a $75 \mathrm{mg}$ oral dose of $[3,4]-{ }^{13} \mathrm{C}$ cholesterol (CDN Isotopes, Point-Claire, Quebec, Canada) mixed in margarine and spread on an English muffin. Fasting blood samples were taken on day $25(24 \mathrm{~h})$, day 26 (48 h), day 27 (72 h), and day $28(96 \mathrm{~h})$ to measure cholesterol absorption. Additionally, following a fasting baseline sample on day 27 , an oral dose of deuterium oxide $(0.7 \mathrm{~g} / \mathrm{kg}$ estimated body water) was given prior to breakfast as a tracer for measuring fractional cholesterol synthesis.

\section{Plasma lipids}

Plasma and red blood cells (RBC) fractions were separated by centrifugation at $3000 \times \mathrm{g}$ for $20 \mathrm{~min}$ and stored at $80^{\circ} \mathrm{C}$. Plasma total cholesterol (TC), high-density lipoprotein cholesterol (HDL-C), and triglycerides (TG) were determined by automated enzymatic methods on a Vitros 350 chemistry analyzer (Ortho-Clinical Diagnostics, Markham, Ontario, Canada). LDL-C concentrations were estimated by the difference method using the Friedewald formula [35].

\section{Cholesterol absorption}

Cholesterol absorption was measured using the single stable isotope tracer approach with the area under the $[3,4]$ ${ }^{13} \mathrm{C}$ cholesterol RBC enrichment curve over $96 \mathrm{~h}$ representing cholesterol absorption. Free cholesterol was extracted from RBC according to established methods [36]. $[3,4]^{-13} \mathrm{C}$ cholesterol enrichments in RBC lipid extracts were determined using on-line gas chromatography/combustion/isotope ratio mass spectrometry approach (Agilent 6890N chromatograph interfaced with a Finnigan Delta V Pulse isotope ratio mass spectrometer (Bremen, Germany). Isotope abundance, expressed in delta (d) per mil (\%o), was calculated using $\mathrm{CO}_{2}$ as a reference gas and further corrected against the international reference standard, Pee Dee Belemnite limestone.

\section{Cholesterol synthesis}

Cholesterol fractional synthesis rate (FSR; \%/day) was quantified using the uptake rate of deuterium from body water into the newly synthesized RBC free cholesterol 
Table 3: Nutrient composition of soymilk and I\% dairy milk ${ }^{\mathbf{a}}$

\begin{tabular}{lccc}
\hline Item & $\begin{array}{c}\text { Study I } \\
\text { I\% Dairy } \\
\text { Milk Diet }\end{array}$ & $\begin{array}{c}\text { Study 2 } \\
\text { Low-fat Soy } \\
\text { Milk Diet }\end{array}$ & $\begin{array}{c}\text { Moderate-fat Soy } \\
\text { Milk Diet }\end{array}$ \\
\hline Calories (kcal) & 100 & 80 & 100 \\
Total fat (g) & 2.5 & 2 & 3.5 \\
Saturated fat (g) & 1.5 & 0 & 0.5 \\
Trans fat (g) & 0 & 0 & 0 \\
Total carbohydrate (g) & 12 & 10 & 10 \\
Fiber (g) & 0 & 6 & 1 \\
Protein (g) & 8 & 0 & 6 \\
Cholesterol & 10 & 0.65 & 0 \\
Plant sterols $(\mathrm{g})$ & 0 & & 0.65 \\
\hline
\end{tabular}

aBased on I serving size $(240 \mathrm{ml})$

pool over $24 \mathrm{~h}$ at the end of each study period [37]. Cholesterol FSR represents the fraction of the rapidly exchangeable central free cholesterol pool that exchanges between the plasma, liver, and intestine [38].

\section{Statistical analyses}

The sample size of 20 subjects was calculated to detect an anticipated difference in LDL-cholesterol levels due to PS treatment of $12 \%(0.54 \mathrm{mmol} / \mathrm{l})$ using an standard deviation of $0.732 \mathrm{mmol} / \mathrm{l}$. The alpha and power were 0.05 and 0.7 , respectively. All data are presented as means \pm SEM. Statistical significance was set at $P<0.05$ for all analyses. Differences in endpoint plasma variables were tested by repeated-measures ANOVA using baseline values as covariates for plasma lipid measurements. To examine the effect of baseline cholesterol concentrations on the lipidlowering efficacy of PS-enriched soymilk consumption in study 1, further analyses of endpoint TC and LDL-C were conducted in a subgroup $(\mathrm{n}=14)$ of subjects with initial LDL-C concentrations above $3.4 \mathrm{mmol} / \mathrm{L}$. For cholesterol absorption, the area under the ${ }^{13} \mathrm{C}$-cholesterol enrichment curves from 24 to $96 \mathrm{~h}$ was calculated with the use of the trapezoidal rule after correction for baseline values. Data were analyzed with SPSS (version 16.0 for Mac, SPSS Inc, Chicago, IL).

\section{Competing interests}

The authors declare that they have no competing interests.

\section{Authors' contributions}

TCR contributed to the collection and analysis of data from study 2 and wrote the initial draft manuscript. YMC contributed to the collection and analysis of data from study 1 and contributed to the revision of the initial draft manuscript. SVH contributed to the analysis of the data and revision of initial draft manuscript. PJH contributed to the experimental design, served as a consultant on the clinical trial, and contributed to the revision of the initial draft manuscript.

\section{Acknowledgements}

Special thanks are extended to Peter Frohlich, Lori Mae Janzen, Darren Speziale, Katherine Leung, Heather Martin, Kimberley Robinson and Khatima Khalloufi for their assistance in conducting these clinical trials. The assistance of Dr. Edward Kesselman in performing physical examinations is acknowledged. We also want to thank study subjects for participating in these studies. Funding: Whitewave Foods, Inc.

\section{References}

I. Mente A, de Koning L, Shannon HS, Anand SS: A systematic review of the evidence supporting a causal link between dietary factors and coronary heart disease. Arch Intern Med 2009, I69(7):659-669.

2. Jones PJ, Demonty I, Chan YM, Herzog Y, Pelled D: Fish-oil esters of plant sterols differ from vegetable-oil sterol esters in triglycerides lowering, carotenoid bioavailability and impact on plasminogen activator inhibitor-I (PAI-I) concentrations in hypercholesterolemic subjects. Lipids Health Dis 2007, 6:28.

3. Vanstone CA, Raeini-Sarjaz M, Parsons WE, Jones PJ: Unesterified plant sterols and stanols lower LDL-cholesterol concentrations equivalently in hypercholesterolemic persons. Am J Clin Nutr 2002, 76(6): I272-I278.

4. Jenkins DJ, Kendall CW, Nguyen TH, Marchie A, Faulkner DA, Ireland C, Josse AR, Vidgen E, Trautwein EA, Lapsley KG, et al.: Effect of plant sterols in combination with other cholesterol-lowering foods. Metabolism 2008, 57(I): 130-139.

5. Demonty I, Ras RT, Knaap HC van der, Duchateau GS, Meijer L, Zock PL, Geleijnse JM, Trautwein EA: Continuous dose-response relationship of the LDL-cholesterol-lowering effect of phytosterol intake. J Nutr 2009, 139(2):27I-284.

6. Berger A, Jones PJ, Abumweis SS: Plant sterols: factors affecting their efficacy and safety as functional food ingredients. Lipids Health Dis 2004, 3:5.

7. Devaraj S, Autret BC, Jialal I: Reduced-calorie orange juice beverage with plant sterols lowers C-reactive protein concentrations and improves the lipid profile in human volunteers. Am J Clin Nutr 2006, 84(4):756-76I.

8. de Jong A, Plat J, Lutjohann D, Mensink RP: Effects of long-term plant sterol or stanol ester consumption on lipid and lipoprotein metabolism in subjects on statin treatment. $\mathrm{Br} J \mathrm{Nutr}$ 2008, 100(5):937-94I.

9. Judd JT, Baer DJ, Chen SC, Clevidence BA, Muesing RA, Kramer M, Meijer GW: Plant sterol esters lower plasma lipids and most carotenoids in mildly hypercholesterolemic adults. Lipids 2002, 37(I):33-42.

10. Jones PJ, Vanstone CA, Raeini-Sarjaz M, St-Onge MP: Phytosterols in low- and nonfat beverages as part of a controlled diet fail to lower plasma lipid levels. J Lipid Res 2003, 44(9): 17। 3-17/9.

II. Hansel B, Nicolle C, Lalanne F, Tondu F, Lassel T, Donazzolo Y, Ferrieres J, Krempf M, Schlienger JL, Verges B, et al.: Effect of low-fat, fermented milk enriched with plant sterols on serum lipid 
profile and oxidative stress in moderate hypercholesterolemia. Am J Clin Nutr 2007, 86(3):790-796.

12. Bricarello LP, Kasinski N, Bertolami MC, Faludi A, Pinto LA, Relvas WG, Izar MC, Ihara SS, Tufik S, Fonseca FA: Comparison between the effects of soymilk and non-fat cow milk on lipid profile and lipid peroxidation in patients with primary hypercholesterolemia. Nutrition 2004, 20(2):200-204.

13. Gardner CD, Messina M, Kiazand A, Morris JL, Franke AA: Effect of two types of soymilk and dairy milk on plasma lipids in hypercholesterolemic adults: a randomized trial. J Am Coll Nutr 2007, 26(6):669-677.

14. Sirtori CR, Pazzucconi F, Colombo L, Battistin P, Bondioli A, Descheemaeker K: Double-blind study of the addition of highprotein soya milk v. cows' milk to the diet of patients with severe hypercholesterolaemia and resistance to or intolerance of statins. Br J Nutr 1999, 82(2):91-96.

15. Lin Y, Meijer GW, Vermeer MA, Trautwein EA: Soy protein enhances the cholesterol-lowering effect of plant stero esters in cholesterol-fed hamsters. J Nutr 2004, 134(I): 143-148.

16. Weidner C, Krempf M, Bard JM, Cazaubiel M, Bell D: Cholesterol lowering effect of a soy drink enriched with plant sterols in a French population with moderate hypercholesterolemia. Lipids Health Dis 2008, 7:35.

17. Xiao CW: Health effects of soy protein and isoflavones in humans. J Nutr 2008, 138(6): I244S-1249S.

18. Mussner MJ, Parhofer KG, Von Bergmann K, Schwandt P, Broedl U, Otto C: Effects of phytosterol ester-enriched margarine on plasma lipoproteins in mild to moderate hypercholesterolemia are related to basal cholesterol and fat intake. Metabolism 2002, 5 I (2): 189-194.

19. Abumweis SS, Barake R, Jones PJ: Plant sterols/stanols as cholesterol lowering agents: A meta-analysis of randomized controlled trials. Food Nutr Res 2008.

20. Ostlund RE Jr, Spilburg CA, Stenson WF: Sitostanol administered in lecithin micelles potently reduces cholesterol absorption in humans. Am / Clin Nutr 1999, 70(5):826-831.

21. Plat J, van Onselen EN, van Heugten MM, Mensink RP: Effects on serum lipids, lipoproteins and fat soluble antioxidant concentrations of consumption frequency of margarines and shortenings enriched with plant stanol esters. Eur J Clin Nutr 2000, 54(9):67|-677.

22. Plat J, Brufau G, Dallinga-Thie GM, Dasselaar M, Mensink RP: A plant stanol yogurt drink alone or combined with a low-dose statin lowers serum triacylglycerol and non-HDL cholesterol in metabolic syndrome patients. J Nutr 2009, I39(6): I |43- I I 49.

23. Naumann E, Plat J, Kester AD, Mensink RP: The baseline serum lipoprotein profile is related to plant stanol induced changes in serum lipoprotein cholesterol and triacylglycerol concentrations. J Am Coll Nutr 2008, 27(I): I | 7-126.

24. Rudkowska I, Abumweis SS, Nicolle C, Jones PJ: Association between non-responsiveness to plant sterol intervention and polymorphisms in cholesterol metabolism genes: a case-control study. Appl Physiol Nutr Metab 2008, 33(4):728-734.

25. Zhao HL, Houweling AH, Vanstone CA, Jew S, Trautwein EA, Duchateau GS, Jones PJ: Genetic Variation in ABC G5/G8 and NPCILI Impact Cholesterol Response to Plant Sterols in Hypercholesterolemic Men. Lipids 2008, 43( I 2): I I 55- I I64.

26. Ikeda I, Tanaka K, Sugano M, Vahouny GV, Gallo LL: Inhibition of cholesterol absorption in rats by plant sterols. J Lipid Res 1988, 29(12): I573-I582.

27. Davis HR Jr, Zhu LJ, Hoos LM, Tetzloff G, Maguire M, Liu J, Yao X, lyer SP, Lam MH, Lund EG, et al: Niemann-Pick CI Like I (NPCILI) is the intestinal phytosterol and cholesterol transporter and a key modulator of whole-body cholesterol homeostasis. J Biol Chem 2004, 279(32):33586-33592.

28. Temel RE, Gebre AK, Parks JS, Rudel LL: Compared with AcylCoA:cholesterol O-acyltransferase (ACAT) I and lecithin:cholesterol acyltransferase, ACAT2 displays the greatest capacity to differentiate cholesterol from sitosterol. J Biol Chem 2003, 278(48):47594-4760I.

29. AbuMweis SS, Vanstone CA, Lichtenstein AH, Jones PJ: Plant sterol consumption frequency affects plasma lipid levels and cholesterol kinetics in humans. Eur J Clin Nutr 2009, 63(6):747-755.

30. Jones PJ, Raeini-Sarjaz M, Ntanios FY, Vanstone CA, Feng JY, Parsons WE: Modulation of plasma lipid levels and cholesterol kinet- ics by phytosterol versus phytostanol esters. J Lipid Res 2000, 4I(5):697-705.

31. Shukla A, Brandsch C, Bettzieche A, Hirche F, Stangl GI, Eder K: Isoflavone-poor soy protein alters the lipid metabolism of rats by SREBP-mediated down-regulation of hepatic genes. J Nutr Biochem 2007, I8(5):3I3-32I.

32. Tovar AR, Murguia F, Cruz C, Hernandez-Pando R, Aguilar-Salinas CA, Pedraza-Chaverri J, Correa-Rotter R, Torres N: A soy protein diet alters hepatic lipid metabolism gene expression and reduces serum lipids and renal fibrogenic cytokines in rats with chronic nephrotic syndrome. J Nutr 2002, I32(9):2562-2569.

33. Wang $Y$, Jones PJ, Ausman LM, Lichtenstein AH: Soy protein reduces triglyceride levels and triglyceride fatty acid fractional synthesis rate in hypercholesterolemic subjects. Atherosclerosis 2004, 173(2):269-275

34. Mifflin MD, St Jeor ST, Hill LA, Scott BJ, Daugherty SA, Koh YO: A new predictive equation for resting energy expenditure in healthy individuals. Am J Clin Nutr 1990, 5 I (2):24I-247.

35. Friedewald WT, Levy RI, Fredrickson DS: Estimation of the concentration of low-density lipoprotein cholesterol in plasma, without use of the preparative ultracentrifuge. Clin Chem 1972, I 8(6):499-502.

36. Folch J, Lees M, Sloane Stanley GH: A simple method for the isolation and purification of total lipides from animal tissues. Biol Chem 1957, 226(I):497-509.

37. Jones PJ, Leitch CA, Li ZC, Connor WE: Human cholesterol synthesis measurement using deuterated water. Theoretical and procedural considerations. Arterioscler Thromb 1993, 13(2):247-253.

38. Jones PJ: Use of deuterated water for measurement of shortterm cholesterol synthesis in humans. Can J Physiol Pharmacol 1990, 68(7):955-959.

Publish with Biomed Central and every scientist can read your work free of charge

"BioMed Central will be the most significant development for disseminating the results of biomedical research in our lifetime. "

Sir Paul Nurse, Cancer Research UK

Your research papers will be:

- available free of charge to the entire biomedical community

- peer reviewed and published immediately upon acceptance

- cited in PubMed and archived on PubMed Central

- yours - you keep the copyright 